\title{
EUGENICS AND UTOPIA: \\ SOCIAL IMAGINARIES OF TECHNOLOGIES FOR DEAFNESS
}

Alana Best, Corinna Howland, Jenny Snapp \& Julie Park

ABSTRACT

A community where everyone speaks Sign? A society where familial deafness ${ }^{1}$ condemns people to sterilisation or death? A world where sign languages are suppressed? All have been historically documented: Martha's Vineyard from 17th-2oth centuries; Germany in the 1930s-40s; internationally, for a century from 1880 . These and other images comprise divergent social imaginaries which are the context for current and future technologies for deafness. These technologies include postnatal genetic and aural testing for deafness, and may in future include prenatal testing. Cochlear implants can enable profoundly deaf people to hear and newborn hearing screening has recently been introduced in New Zealand. Sign language is another technology whereby deaf people can communicate, create poetry and drama and tell jokes; yet its fortunes have fluctuated over time with oralism's dominance. Our article draws on two small ethnographic studies in Auckland: one with two families with hereditary deafness; the other with two families and one young adult who had recently chosen cochlear implants, to suggest that individual and societal moral reasoning on the contested issues of technologies for deafness is embedded in different social imaginaries of normalcy.

INTRODUCTION: DEAF IMAGINARIES

Brandon and Sarah described their son, Seth, as 'the perfect baby' before his hearing test, given when he was over a year old. For Sarah the time she had as a new mother with Seth before he was diagnosed with his hearing loss was precious. She described being able to enjoy being a new mother without having to contend with the stress of a cochlear implant or the diagnosis of deafness.

In contrast, Sally emailed that: 'after Marsha was identified [as op- 
posed to diagnosed $]^{2}$ Deaf, it felt plausible to celebrate the fact that we bore a Deaf baby and this strengthened our social identity as a Deaf family and this alone was an asset for the Deaf community. ${ }^{3}$

Deafness may be regarded as a disability which medical technologies can fix; a sensory difference which can be socially accommodated through societal response, such as through interpreters, hearing assistance of various kinds, and broader use of sign language. Or deafness may be regarded as not a disability at all, but a cultural variation to be celebrated, acknowledged and respected in the hearing world - or some shifting combination of the above. Deafness may be analysed as a predicament (Shakespeare, 2006; Taylor, 2002), or a series of predicaments: only ten percent of deaf babies are born into Deaf families, so the cultural reproduction of a Deaf world is a continuing struggle. Whether they regard deafness as a disability or not, $\mathrm{D} /$ deaf people and families are forced to frame deafness in terms of disability in order to access the resources they need to participate in society (Morton 2012). And in seeking 'normal' hearing and orality for themselves and their children via hearing aids or cochlear implants, deaf people have an outward sign of their deafness/difference.

We draw on concepts of 'social imaginaries', 'technologies' and 'predicament', and build on the contributions to SITES (2006), dedicated to understanding different Cultural Positions in New Zealand's Deaf World, to explore some current and anticipated future 'technologies for deafness'. These include genetic testing, newborn hearing screening, cochlear implants, and New Zealand Sign Language. We argue that widely differing positions on these networked technologies between and across D/deaf and Hearing communities located in divergent social imaginaries reveal competing visions of normalcy. Deaf imaginaries of these technologies are marked by two specific and contrasting historical narratives, recorded in books that our participants referred to, and indexed in fieldwork conversations with members of the Deaf community. We refer to these as social imaginaries of dystopia and utopia, where these are understood in a lay sense as exclusionary and inclusive respectively (see also Levitas 2003; Morton 2012).

The dystopic imaginary, that encompasses both latent and explicit fears of cultural genocide and the struggle for cultural reproduction, is an account of extreme stigmatisation of the $\mathrm{D} /$ deaf. It is rooted in the demonisation of sign language from the 188 os until the early 1990 os and the Nazi persecution of the deaf community in the 1930 and 40 . This can sometimes manifest in the present as a reserved response to hearing technologies, such as genetic testing or cochlear implants, which seek to 'fix' or 'correct'. For in doing so, these 
posit hearing as the norm, render deafness as an 'abnormality' or 'disability', and most importantly may pose a threat to cultural reproduction through sign language. The second imaginary indexes the utopian possibilities of a fully signing community, which occurred in Martha's Vineyard from the mid 17th-2oth centuries. Within this imaginary utopia, Deafness is posited as a normal occurrence, a cultural variation, and normalcy is facilitated through the technology of sign language used by all citizens.

\section{ETHNOGRAPHIC CONTEXTS: TWO CASE STUDIES}

This paper is based on two small case studies conducted in Auckland during 2012. In the first, Corinna, Alana, and Julie ${ }^{4}$ worked with two Deaf families to explore their everyday lives and their thoughts on genetic testing, reproductive technologies, and other technologies for deafness. ${ }^{5}$ The first family comprises Victoria and Greg, who were expecting their first baby at the time of our study. Victoria was born in Latvia to hearing parents who discovered she was deaf at the age of 18 months. Her family theorises that her deafness is acquired, not inherited. Greg, in contrast, grew up in a signing deaf family in South Africa. He has never been genetically tested, but his father speculates that his family's deafness is inherited. Victoria and Greg did not know whether their baby would be born deaf, which added to the excitement of their pregnancy. The second family comprises Sally, Tom, and their daughter Marsha, who is also deaf. ${ }^{6}$ Sally and her brother were born deaf to hearing parents, while Tom was the sole deaf person in his family. However, Sally and Tom carry a known gene for deafness. Both sets of families use New Zealand Sign Language (NZSL) as their main form of communication, and read and write English (and other languages) with varying degrees of ease. They are enthusiastic members of the Deaf community and were very open in explaining their views on various technologies for deafness and Deaf history. They also reminded us that within the Deaf community there are a wide range of views, some very different from their own. These four adult participants grew up in four different countries, only one being a New Zealander by birth. ${ }^{7}$ However, they had all lived in Auckland for several years.

In the second case study, Jenny examined the experiences and decision-making processes of hearing parents of deaf children, who had opted to use the technology of cochlear implants (CIs) to enable their children to hear. A CI is a device which is surgically inserted into the inner ear, and which allows the wearer to hear by converting sound waves into electrical impulses that are then transmitted via the inserted device directly to the nervous system. The mechanical workings of a normal human ear are replaced by the device, but the 
human brain must still decipher the electrical impulses as 'sound'. Jenny was introduced to her participants by the staff at Hearing House, a not-for-profit organisation devoted to the habilitation of people (usually young children) who have cochlear implants. She worked with two families with young deaf children and one young man who had decided as an adult to have CIs. None of the people in Jenny's study were known to have hereditary deafness. The first family consisted of a young girl called Kate and her grandparents, Mary and Jamie. Kate has a condition called audio neuropathy, which causes hearing levels to fluctuate and progressively decline. At the time of Jenny's research, Kate had one CI and one conventional hearing aid-this arrangement seemed to give Kate's language acquisition the boost it needed. The second family, comprising Sarah, Brandon, and their son Seth, were surprised when Seth was born deaf as they had undertaken prenatal testing for other conditions. ${ }^{8}$ They decided to get Seth implanted with CIs in both ears at eighteen months. Following Seth's birth, Sarah and Brandon also undertook genetic testing for deafness, as they were concerned that if they conceived again there would be a possibility that their second child would also be deaf. Sarah particularly felt that she could not handle the stress of having another deaf child. They had not received a result. Neil, the young man, had acquired deafness from meningitis as a toddler. $\mathrm{He}$ retained some hearing in one ear and developed speech using a hearing aid before eventually seeking out a CI as an adult.

THEORETICAL FRAMEWORKS: TECHNOLOGIES, SOCIAL IMAGINARIES, NORMALCY AND PREDICAMENT

In each of the case studies, our participants discussed their engagement with, and understanding of, a wide range of technologies for deafness. Technologies, as we use the concept here, consist of networked material objects, systems of knowledge, conventional practices, and the meanings with which they are imbued, together creating apparently coherent entities which articulate with the contexts in which they are embedded. In this usage of technologies, we follow the work of Latour (1987), Brodwin (2000), and others, who focus on how materiality and meaning are imbricated at nodal points in science and technology networks. Sign language, cochlear devices, newborn hearing screening and genetic testing are all technologies in which meaning and material coalesce.

As we talked to the different families about their experiences of technologies for deafness, repeated narratives, images and ideas emerged. Following Crapanzano (2010 [2004]) and especially Taylor (2002; 2007) we use the term 'social imaginaries' to refer to the ways in which community members imagine their social surroundings, indicated by these images, notions and stories. Tay- 
lor (2002:91) adopted the term 'imaginaries', acknowledging Benedict Anderson's and others contributions, to indicate that they exist at a deeper level than is conveyed through the term 'theory'. He was concerned with how 'ordinary people "imagine" their social surroundings, and [argued that] this is often not expressed in theoretical terms; it is carried in images, stories and legends' (Taylor, 2002:106). He wrote, '[social imaginary] is what enables, through making sense of, the practices of a society' (Taylor, 2002: 91). It makes community possible and enables a shared sense of legitimacy. Taylor's work is concerned with the moral order of Western modernity and he insists that the concept of social imaginaries should be used only when notions and images are widely shared in society, as they refer to embedded understandings of how things and people fit together. While we agree, we suggest this sharing may not be universal and have found that the concept is useful to think with in relation to some more specific themes, including shared understandings of what is normal. Within the Deaf community, for example, (hypothetical) prenatal testing for deafness is widely assimilated into social imaginaries of eugenic technologies and cultural genocide and disavowed, but other technical devices, such as cochlear implants and hearing tests may be interpreted in this way by some community members and not by others.

Taylor acknowledges that social imaginaries are complex, and include both factual (how things usually go) and normative (how things ought to go) elements. The term 'predicament', which he uses throughout his discussion, invokes an active subject who is involved in practices and is aware of the broader background, the normative element which indexes a moral order. It is the practices plus the background understanding of the moral order together that make society possible. Concepts of normalcy, as Goffman (1963) theorised, create conditions for stigmatising processes which occur in the gap between what is, and what ought to be. Stigma, contesting stigma and impression management is part of the $\mathrm{D} /$ deaf predicament. Predicament has, as Taylor says, 'a time and space component' (Taylor, 2002:109). Actors are aware of their 'whole predicament in time and space, among others and in history'. We find this concept of predicament (with its agentive and temporal implications) useful analytically in our study of technologies for deafness, as we indicate below in relation to Shakespeare's (2006) work.

Debates about technologies for deafness reveal the different social imaginaries in which they are embedded, such as Deafness as normal cultural variation; or deafness as a medical problem of human deficit; or even as 'unworthy life'. Consequently, social imaginaries -consisting of stories and images of disability, eugenics, genocide and culture - are key to our discussion of technologies for 
deafness. They transmit and reproduce powerful, albeit divergent, conceptions of what constitutes normalcy, which Hacking (1996), like Taylor, argues is signifier of both fact and value, of what is and what ought to be. Moreover, if social imaginaries of normalcy are differentially shared, the meanings of technologies may be unanticipated - by the enquiring anthropologists as well as by some community members. This was the case when two Deaf research participants, Tom and Sally, described to Alana and Corinna what they had experienced as a shockingly hostile reaction by one of their friends in the Deaf community when they told him about the genetic tests they had had after their baby daughter was found to be deaf.

\section{TROUBLING TECHNOLOGIES}

Tom and Sally's Story

Sally and Tom were surprised and puzzled when their daughter, Marsha, was born deaf, as until then they did not think that their own deafness was inherited. Living in England when she was born, they decided to request genetic testing and found that they were each carrying one of the common recessive mutations (connexin 26 on chromosome 13) which can result in deafness. They told us that they found their session with the genetic counsellor very informative and interesting and were pleased that they had gone to the trouble of finding out. For them it was an educational experience. But the reaction of one of their Deaf friends astonished and shocked them. As Sally told us in our first formal interview with her and Tom:

And he [their friend] just went off his rocker at us and he was very sensitive about that and he said, 'You know what, the genetic people help to eradicate Deafness and it's all hearing people that are in control of that, and you're giving information about the Deaf community to those people to use it against us'. And we thought, 'Oh goodness, we didn't mean to do that'. We didn't think that that was what we were doing, it was just for us - we never thought that, of his view that the information was going to be used against Deaf people in the Deaf community to eradicate Deafness. And so we thought, (gasp) 'we were responsible for the eradication of the Deaf community' from then on in. So it was a real shock to us (Jan 2012).

Sally and Tom explained that as time went on and they learned more, they realised that despite what their friend had said they were not betraying the Deaf community by trying to understand more about their Deafness and they 
did not need to feel guilty. However, this made them very aware that some people within the Deaf community were highly sensitive about all forms of genetic testing for Deafness. As later interviews revealed, both Sally and Tom thought that prenatal testing for deafness and especially the idea that a pregnancy might be terminated or prevented because of deafness was totally abhorrent, eugenic and comparable to genocide. But, unlike their friend, they did not extend this social imaginary to personal genetic testing undertaken to become better informed.

\section{Belaboured Binaries}

Dystopian and utopian imaginaries inform approaches to disability which are often conceptualised as a continuum from medical to social. Briefly, a social model posits society as disabling, whereas a medical model posits the impairment as disabling. The New Zealand Disability Strategy (Ministry of Social Development, 2001) locates itself firmly within the social model, declaring in the initial 'Summary' that disability occurs when no account is taken of the impairments that people have. Individuals or organisations sometimes position themselves in terms of opposed ends of this continuum. For example, the Disabled Person's Assembly (DPA) embraces a social model of disability, and specifically rejects a medical model, as do some Deaf people (DPA, 2000). More usually however, both social models and medical models are intertwined in complex ways. A genetic difference itself may be experienced as limiting ones' participation in society and enjoyment of life, through pain, fatigue and a range of health issues. In addition, social attitudes to difference, reflected in barriers to access, are also disabling.

We agree with Tom Shakespeare (2006) that continuing the debate in binary terms of social versus medical models of disability is unproductive and, in some cases, destructive. Instead we have adopted Shakespeare's (and Tayor's) concept of 'predicament' as a more useful approach. Predicament, in Shakespeare's terms, refuses the victimhood which both the social and the medical model may imply; encouraging a multidimensional approach which may include working in partnership with scientists, influencing social policy, creating enabling social surroundings, acknowledging pain and impairment, and (as in the case of Deaf world spokespeople) contesting the whole idea of disability. It accords agency to the actors confronting the predicament, yet it does not deny struggle and though cognisant of the past, it is future-oriented (Shakespeare, 2006:63). Our use of the concept of predicament is not intended to replace the concept of disability, but to lead to a more open-ended enquiry in which a predicament may or may not be emically conceptualised in terms of disability. 
Like Sally and Tom, many (but not all) people who are Deaf see Deafness not as disability, but as cultural variation and part of normalcy. Arguably, the key component of claims to Deafness as culture is the use of a different language in New Zealand this is New Zealand Sign Language, the nation's third official language. However, these claims are complicated and confounded by the fact that around 90 percent of children who are born deaf are born into hearing families, making cultural reproduction always tenuous. ${ }^{9}$ We were repeatedly told this by our participants, and found it in many written sources also (e.g., Mehl and Thomson, 2002). These hearing families are unlikely to know Sign language and are likely - initially at least - to see deafness as a loss, a disability, and a cause of grief and sometimes guilt. In this situation, the survival of Deaf language and culture is a constant struggle. Those families which do have inherited deafness and two or more generations of Deaf members, as well as extra-familial organisations such as Deaf Clubs or schools which teach Sign, feel they have a crucial role in the maintenance and transmission of Deaf language and culture. In literature about Deafness and in our interviews, Deaf people raised in hearing families, on finding Sign Language and Deaf friends using it, spoke about 'coming home'. But the continued existence of this cultural home is a result of struggle. While our larger project that these small studies contribute to is specifically about everyday ethics concerning reproduction and genetics, in our work with Deaf people we found that other technologies are also implicated as threats to cultural reproduction. So, for example, cochlear implants may be described by some members of the Deaf community in much the same way as genetic testing and associated reproductive technologies. This is because for many in the community, Sign language is fundamental to cultural continuity and to personal identity as Deaf, and cochlear implants and even hearing aids, may mean that Sign language is under threat (Lindgren, Deluca Napoli, 2008). But this is only the case if Sign is discouraged as a corollary of having hearing aids or implants, as it sometimes has been.

When a child is implanted with a cochlear implant, often parents are told to only speak to their child, and to avoid Sign language, as a part of the protocol for auditory-verbal therapy. Once a child begins to acquire language this push for verbal-only communication is often lessened. However, as most deaf children are born to hearing parents who have no knowledge of Sign language, and who have expectations of their child participating in the hearing world, there have been concerns amongst the Deaf community for Sign language's survival. For some members of the Deaf community, the threat of physical genocide via genetic screening plus terminations and cultural genocide via newborn screening plus CIs are both feared, but CIs and newborn screening are present realities whereas prenatal screening is not. The absolute normalcy of hearing 
as a fact and value (Hacking, 1996) for those who can hear was nowhere more clear than when Jenny asked the hearing parents and caregiving grandparent of the two youngsters who had had CIs about the 'decision-making process' which led them to have their children implanted. She found that the whole concept of a decision-making process was something of a misconception, for it was not a process and hardly a decision. As Sarah said in relation to her son, Seth: 'This is what's available and why wouldn't we? ... So I think, yeah, there wasn't really a lot of thought that went into it. It was "This is what we've got to do to give him the best start in life"' Similarly Jamie, talking about her granddaughter, Kate, said '[I]f there was a chance Kate could hear, we were going to take it.' She wanted to be able to say to Kate when she was older that they had tried everything that might help her with oral communication. Consequently, CIs were celebrated by these parents and caregivers as a useful technology which would help normalise their children and allow them to succeed in the hearing world.

These two sets of caregivers for young children also used the image of coming home in their narratives. But, in contrast to Deaf people (such as our families with inherited deafness) who have experienced Sign language as a homecoming, for these parents it was Hearing House that was home. Sarah told Jenny, 'I can remember walking in here and just going, "This place feels like home, you know?" And that's what we needed in our life right then.... [Hearing House] has been our rock. Sarah, as a parent, longed to find a place where her experiences as a hearing parent with a deaf child could be normalised. Hearing House provided her with that environment, and a community that had developed shared imaginaries surrounding deafness as a physical disability which could be corrected by surgery and supportive habilitation, allowing the children to be 'as normal as', as Jamie related. In contrast, and like the Deaf couples, the young adult in Jenny's study, Neil, found a second home as an adult with a $\mathrm{CI}$ in the Deaf community.

Neil was raised orally and attended mainstream schools. Around fifteen or sixteen he was offered the possibility of having a CI. He declined, convinced he was doing just fine with a hearing aid. He was also involved in rugby and SCUBA diving at the time, two activities that are not overly compatible with a CI. ${ }^{10}$ After a year at university, Neil found his hearing could not give him sufficient aural access in large, noisy lecture theatres, so he opted for a CI. When Jenny met him three years later, he said that until he had his CI he did not know what he was missing, hearing-wise, but, on the downside, he has had to limit his favourite sports. He explained that with his CI he can make friends with a wider range of hearing people - not just those who 'put up with' his hearing 
issues. He had also begun to learn NzsL. He had always had deaf friends and Sign language enabled him to be more at home in the Deaf community as well.

The personal circumstances of the families (inherited versus acquired deafness) in our studies go some way to explaining differing perceptions of D/ deafness and deployment of technologies. However one can also find hearing families with a child with acquired deafness, or hearing children of deaf adults who are very strong supporters of Sign language along with oral communication (Laing, 2006; Walton, 2006) and families with inherited deafness who also opt for all modalities (companion paper, this issue). Without discounting the importance of the families' familiarity with $\mathrm{D} /$ deafness, we suggest that the remembered and recorded histories of the D/deaf can also account for the different meanings of these technologies. As Taylor (2007) has argued, stories and images are crucial to social imaginaries. While the reaction of Tom and Sally's friend might be considered extreme - and they suggested this too - the relatively recent history of deaf people and of Sign language has strong dystopian threads.

Here we briefly sketch the fragments of Deaf history which provide context for the frequent references to genocide and eugenics by the participants. Eugenic ideologies and programmes were not confined to Germany but flourished in many countries, including New Zealand (Taylor, 2005). However, the stark history of eugenics and genocide in Nazi Germany was a key reference point as the archetypal dystopian imaginary. In Germany in the 1930s, children and adults with presumed inherited deafness (but in practice with any form of deafness) were identified as members of the category of people with inherited diseases in the 'racial purity policy' of Hitler and the Nazi regime and deemed outside the community of the Third Reich. This 'T4' policy, named after the address of its place of origin, 'Tiergarten 4' in Berlin, began in July 1933 with the creation of a register and documentation of genealogies, which provided grounds for sterilisation, proceeded to forced abortions in 1935 and then, in 1939, murder - called 'euthanasia' in the policy (Biesold, 2002). During the execution of the $\mathrm{T}_{4}$ policy, doctors, directors of institutions, nurses, social workers, teachers, and, to a lesser extent, the general public, participated.

After the end of the war, disabled people who were survivors of these killing places or of sterilisation received no restitution from their government unless it could be proved that their condition was not inherited, with the obvious implication that the lives of people with inherited conditions were unworthy and forced sterilisation was justified. In 1998 Friedlander, an historian of the Nazi period, wrote in his introduction to Biesold's Crying Hands, 'To this day, the 
German state has not fully recognised and compensated the disabled, including the deaf, for their persecution during the Nazi period' (Biesold, 2002:12).

This schematic outline of recent German history familiar to our participants, provides some insights into why Sally and Tom's English friend was so outraged that they had had genetic testing, and why he thought the consequences could be so dire, although neither they (nor we) knew the exact personal circumstances which led to his outburst. Although in late 20 th and early $21^{\text {st }}$ century Britain or New Zealand sterilisations or murders are not contemplated, current fears centre on possible genetic testing and prenatal screening, and the possibility of gentle or not-so-gentle persuasion to avoid giving birth to deaf babies. This is not a current reality, given that only about half of all deafness is thought to be genetic, and even that portion which is genetic has complex and varied causation (Nance, 2003). Nevertheless the danger is vividly imagined and experienced as a threat to the preservation and continuity of Deaf culture. Consequently, genetic selection against deafness was found to be distasteful and morally wrong by both the families with inherited deafness. It amounted to cultural genocide. In a follow-up email to our interview, Sally explained: 'Imagine that people could abort a baby if they had known it as Maori and that's the same for some Deaf people to feel if people knew the baby was Deaf and wanted to abort' ( 7 th Feb. 2012). However, they were not against genetic testing for other, 'serious', conditions, believing that parents should have a choice in such matters.

While much contemporary medical discourse around prenatal care concerns individual choice, in practice the available and appropriate choices are heavily circumscribed. This was clear to Corinna and Julie when they accompanied Victoria on an antenatal visit which involved an ultrasound scan.

Victoria could feel her baby moving around but could not, of course, hear the heartbeat, so it was very special for her to see the ultrasound image and she wanted to prolong the moment. She begged the midwife to continue the scan a little longer. But she [midwife] said she could not as she had to go and also the sound of the scan was not good for the baby's hearing. Victoria said, 'Well, what if the baby's Deaf?' and the midwife said, 'Well, what if the baby's hearing?' Victoria said (laughing), 'Well maybe we'll just do it anyway and damage the baby's hearing, then they'll be Deaf like us. This was clearly meant as a joke, however it prompted the midwife to smile disconcertedly and say, 'Well, that's your choice' (Best, Howland Park, 2012:24-5). 
In this vignette, the rhetoric of individual choice represents a safe default position, which the midwife reverts to in order to avoid overt criticism of the couple's dark humour and implicit desire for a Deaf child. However it was evident that this 'choice' was morally and socially troubling for the midwife. During her second interview Victoria alluded to the same issue of choice:

But it's like do we have a choice to modify the gene, could we remove the hearing gene and replace it with deaf gene? ... Why not? But what would other people's reactions in New Zealand be? Objecting? There'll be an outcry. ${ }^{11}$

Victoria was quite clear that when or if genetic technologies for deafness become available, they will be slotted into the existing social imaginaries which produce deafness as a disability. Scully (2008:60-63) discusses two contrasting cases which clearly demonstrate these imaginaries in action in the United States and Australia. In one family the culturally Deaf parents expressed a preference for having a deaf child, and in the other a hearing-impaired couple wished to ensure that their embryo would grow into a child with normal hearing. As Victoria opined, in the first case there was a media uproar and intensive ethics debate. In the second, there was very little ethical discussion. Only in relation to the first case did some people, a minority, champion the couple's right to have a baby and to have choice in that. In the second case there was no suggestion that Deafness was simply a different way of being in the world', as Scully (2008:61) puts it.

But there are more immediate concerns for Victoria, Sally and their partners centring round other technologies, such as universal newborn hearing screening, cochlear implants or hearing aids. Like genetic tests, they are part of more diffuse and networked technologies embedded in oralism and ultimately in social imaginaries of normalcy which create Deafness as something to be fixed through medical and/or educational means.

Universal newborn hearing screening is a common method to test for early deafness. It has become standard procedure in many countries, including New Zealand where a national programme began in 2010. Tests are performed to identify hearing loss and prevent developmental delays due to lack of language acquisition. This non-invasive screening, undertaken within a month of birth, has been introduced as an addition to an older screening panel undertaken soon after birth that includes tests for phenylketonuria and cystic fibrosis, among others. The screening exists to make sure that newborns are healthy, but also to determine whether they are 'normal'. 
It was within a critique of this social imaginary that Victoria described to us and various others present (a total of six different times throughout the research which signifies the importance of this issue for her), the discriminatory attitudes inherent in the newborn hearing screening test programme:

And I don't know if you've heard about ... newborn baby hearing screening test? They've got a programme running and the parents and mothers who give birth, they go straight away to the screening test to see if they're hearing or not. ... so when I found out about the screening test and ... what they actually say on the results-so if your baby is hearing or deaf, or has hearing loss that they've 'failed' the test... it's a big red screen that comes up - I sort of thought, ... well, would we be happy to see that on the screen about our babyyou know that they've 'failed'? It's kind ... for us, that's the opposite effect for us, we'd celebrate if our child was Deaf, because that would make them unique. But for hearing parents who have no knowledge or no experience about being deaf and don't know the Deaf community, if they saw that on the screen that their child had 'failed' - I think they'd be heartbroken and psychologically it would actually affect them: and possibly for the rest of their lives..... And you know, not a green for pass and a red for fail, but maybe change the colours, like blue or red or some other colour, that you know, that they're either deaf or they're hearing so that it's neutral.

As this heartfelt comment shows, the taken-for-granted normalisation of hearing is all pervasive and takes on a moral dimension through the use of the traffic light colours of red and green and the achievement-oriented standards of pass and fail.

During our meeting with Victoria and Greg to finalise our report, we learned that Victoria had written a letter to her District Health Board discussing the negative elements of this testing process. The Board replied that the format had been changed before her complaint was received, to create a more neutral test. For example instead of 'fail', the term 'referral' (to an audiologist) was used. Victoria and Greg were pleased with this change. However, when their son went through hearing screening soon after birth, they asked about the options given to parents whose babies were found to be deaf (or 'hearing impaired' as the tester called it). They were critical of these choices because they included only referrals to audiologists and information about hearing aids: nothing about Sign language. This is despite the fact that Sign language has been an official language of New Zealand since 2006 (New Zealand Sign Language 
Act 2006), and children's access to it as a medium of education is enshrined in Objective 3 of The New Zealand Disability Strategy (Ministry of Social Development, 2001), which was mandated by the New Zealand Public Health and Disability Act 2000. As it eventuated, Victoria and Greg's son was not deaf.

UTOPIAN POSSIBILITIES: SIGN LANGUAGE AND BILINGUALISM

In our discussions, both families with inherited deafness were at pains to present the birth of genetically Deaf children as 'unique' (Sally, second interview) or a 'gift' (Victoria, second interview), which ensures the perpetuation of NZSL and the New Zealand Deaf community. For example, Sally stated in a followup email to our second interview the celebratory quote we used to open this paper. Likewise, while Victoria and Greg were expecting their baby, there was ongoing speculation about whether their baby would be deaf or hearing. They were very excited about the upcoming 'surprise', and articulated both the benefits and challenges of either outcome. As described above, however, they also joked about various methods of ensuring the baby would be deaf.

From our discussions with participants as well as from the literature we understand Sign as the bedrock of Deaf culture and Deaf community and acknowledge the threat to cultural continuity from technologies which do not support Sign language. Sacks (1991:146) wrote of the tender feelings which Deaf people hold towards their Sign language and their fear that it might be taken from them, and therefore that they might be deprived of their culture. Such cultural interruption has happened several times in history, such as after the infamous 1880 International Congress of Educators of the Deaf in Milan (Sacks, 1991:27) where oralism won the day and Sign was proscribed in deaf education, in the ousting of Sign from New Zealand schools from the 1880s until the early 1990 s (along with Māori and other non-English languages) with very negative consequences for many children's intellectual development, and in recent times in some places, forbidding children who were having cochlear implants from learning Sign. Hostility between proponents of oral communication and those encouraging Sign have their roots here. This is often underpinned by a denigration of Sign as not a real language, as animalist, and limited. In this international and local history there are enough examples of cultural genocide to fuel any number of contemporary dystopian imaginaries (Sacks, 1991).

While these loom large in Deaf history, they are not the only imaginaries. The history of Deaf culture also includes accounts of rare communities where everyone spoke Sign and all community members, not only those who were Deaf, were involved in cultural transmission. Martha's Vineyard in Massachusetts 
was one such place. This is widely known in the Deaf community, and was documented in an historical ethnography by Nora Ellen Groce (1985; see also McDermott Varenne, 1995).

From 1634 settlers arrived in The Vineyard from circumscribed areas of Kent in England, bringing with them, as far as Groce could ascertain, not just recessive mutations for deafness but the local Sign language. In all, there were about 400 people on the island in 1700 and roughly half were from Kent. From 1710 there was very little in-migration and few reasons to travel off island. Family members settled near one another and neighbours tended to intermarry, hence the scene was set for cousin marriage. As the generations followed, the chances of couples with the recessive gene marrying increased. It was among these folk that Sign language became one of the two ordinary ways of communicating, and deaf people were deemed no more exceptional than someone who 'had trouble with his wrist' (Interviewee, quoted by Groce, 1985:51). By the time Groce did her work, this signing community was only a memory, but from first European settlement until the early 2oth century, everyone learned Sign and hearing people learned Sign and English. Groce demonstrates that Deaf people in this community suffered no economic or social disadvantage, being Deaf was quite explicitly not seen as a disability. Additionally, the Martha's Vineyard Sign language later became an important contributor to what is now American Sign Language. It was only when the communities became open to the outside world with many summer visitors arriving, residents moving away, and especially children being sent away to Deaf boarding schools from the mid 19th century, that extensive out-marriage greatly reduced the frequency of genes related to deafness, and both Sign language and Deaf people became rare.

Today, around the world, a comparable acceptance of Deaf as normal and of Sign as the main means of communication can be found within certain organisations, such as Deaf clubs, Gallaudet University in the United States, and among family and friendship groups. For some children and young people, this is also occurring within their school environment where all the children begin learning Sign when Deaf children join their class. This was happening in the classroom of Marsha, Sally and Tom's daughter.

At home and with Deaf friends, Sally and Tom can communicate and relax, but for them social situations in the hearing world could be isolating and frustrating: Tom explained:

When we are invited to weddings or parties or those kind of things with hearing people, we'll only stay for a short time. Just mainly be- 
cause of the communication issues. We've both had enough of that in our past so we prefer not to have to be in it, we're not as interested in that kind of environment. We'd prefer to go home (Interview 2).

Likewise, at our initial meeting with Victoria and Greg to discuss the research, Victoria explained that she came from a hearing family whose members do not Sign, whereas Greg was from a Deaf family where people signed. Victoria said that she felt more at home in Greg's family because everyone signs and in a group setting they can have in depth conversations on all sorts of topics, like politics. But in a group setting in her own family, the conversation is more superficial because of communication difficulties. She described herself as more of an observer, explaining that it is really only when one-on-one that she can have in depth conversations. Both Greg and Victoria spoke about the visual humour and the depth of language in families like Greg's. Tom, who was brought up in an oralist family, also described learning Sign language and being immersed in a Deaf club as like coming home. As Tom and Sally explained, their deafness only becomes a problem when they are in other social contexts and the problem is not a disability but that 'other people can't speak Sign'.

Sally explained to us that in her view: 'Deaf is definitely separate from other [disability groups], it's a communication, it's a language. So when you've got language, you've got culture and you have belonging and you have shared experience' (Best, Howland Park, 2012). For these two families with inherited deafness, being Deaf is a way of life or culture and it is not a disability. But to access resources (such as government funding for Sign language interpreters) and opportunities in the hearing world (such as paid employment), deafness as disability has to be strategically utilised. It cannot be escaped. This is part of their predicament.

Given these understandings, each of our Deaf families wanted a bi-lingual education for their children: an educational experience better than their own where the children would have access to both Sign language and written/vocal language (see also Buzzard Nicholson, 2006; Morton 2012). They stressed the importance of having visual perception included in the curriculum. As Rachel McKee (2001) phrased it in her book's title, Deaf are 'people of the eye. These families want curriculum development to be in the hands of Deaf educators, who, they strongly believe, have a better understanding of how D/deaf children should be educated. Deaf students can learn both languages either in school or at home, but they emphasised that education must be accessible by either language. 
Wanting the best for their children and Deaf communities, Victoria, Greg, Sally and Tom were aware of the dystopic and utopic pasts of Deaf communities internationally. New technologies were assessed against these historical imaginaries. In their everyday lives these couples actively created a Deaf world in which they and their children could feel at home. The women especially worked at building understandings of Deaf worlds in society at large in both their voluntary and paid work. This struggle within the dominant oralist-hearing technologies and stigmatised social imaginaries of deafness as disability was on-going and is well illustrated by the immediate acceptance by the other sets of caregivers that their children should, as a matter of natural course, have access to orality via CIs, and their unwitting disregard of Sign language. The history of Deaf struggle against stigma is unknown to them. Neil, however, wanted for himself, as did the parents with inherited deafness for their children, access to both orality and to the Deaf world. Neil's response to his predicament was to speak Sign language, use his $\mathrm{CI}$ and live in hearing and Deaf worlds. Sally, Tom and Marsha's response was to be immersed in Deaf culture and Sign language, and to strategically use the education system, both Deaf school and mainstream schools, to give Marsha the best possible access to spoken and written English and education more generally. This was by no means easy. Seth's parents who had 'of course' agreed to a CI for their son, and had fund-raised so that he could have a CI in each ear, were, along with Seth, immersed in habilitation. However, they were already a little concerned that as a trade off to achieve normalcy in the hearing world, he now had an obvious device behind his ears and might still be teased for being different. In avoiding one stigma, they were concerned that they may have created the conditions for another. Kate's grandmother was a little concerned that Kate might be teased for her less-than-perfect hearing and speech, even with her hearing aid. Kate's CI was a strategic response to this predicament.

\section{CONCLUDING COMMENTS}

Throughout our work with D/deaf people, they shared their experiences of deafness and various related technologies. These include Deafness experienced as a minority culture defined by a language which is always in danger of extinction and is especially threatened by some new technologies; and oral/ aural communication as the bedrock of normalcy in the wider community. So prevailing is this perception of oral/aural normalcy that 'of course' parents and caregivers will accept cochlear implants without a second thought, and parents of babies with hearing impairments or deafness will not be offered the 
technology of Sign language as part of the routines of referral. Within these technologies are echoes of dystopian, historically-situated social imaginaries - of oralism and cultural genocide. As Taylor (2002) discussed, the practices and broader understandings of social imaginaries are bound up in one another, creating, at the same time as enacting, the prevailing moral order. But the dominant moral order is not the only possible one - as Taylor also acknowledged when discussing change. Certain technologies, such as widespread use of Sign language, provide recourse to a possible utopian future where the cultural transmission of Deafness can be secured. Consequently, the question that we authors wish to leave our readers with is this: Is it possible for us all to bracket discourses of disability versus normalcy, and social versus medical disability, and concentrate on the concept of predicament - which can apply to all of us at different times in our lives, and includes many situations, in addition to those we now label 'disability'? Can we envisage a Health and Predicament Commissioner? A Health and Predicament Strategy? Predicament Support Services? Individuals, families, groups and organisations could then formulate the nature of and changes in their predicament, which might include concepts of disability, and be empowered by networked technologies appropriate to their own formulation to enable optimal lives, social participation, and human rights. In the context of the wider society and D/deafness, this would include support for Deaf culture and language -what McKee (2006:162), drawing on other scholars' work, calls 'deference'; and support for technologies to enable hearing. A focus on predicament is relevant, beyond deaf and hearing, to the beginnings and ends of lives and many phases in between.

\section{ACKNOWLEDGEMENTS}

The authors have many people to thank: Tricia Laing and Sabine Muller for initial advice and Sabine for liaising with members of the Deaf community to introduce and explain our study and invite participants; the staff of Hearing House; the professional iSign interpreters, especially Kelly who interpreted almost every Auckland interview and interpreted during our training and feedback sessions; our colleagues at the University of Otago, especially Ruth Fitzgerald and Michael Legge; the social anthropology writing group at the University of Auckland for their helpful comments on a draft; our two international reviewers for their helpful critical comments; and most important of all, our participants, for their great generosity in sharing their experiences. We acknowledge the summer scholarships which were provided by New Zealand Royal Society Marsden Fund project, 'Troubling Choice', and the support of the Department of Anthropology of The University of Auckland which housed the students. 
NOTES

1 In line with current practice we use Deaf with a capital D to refer to the Deaf world and Deaf culture and with a small d to refer to physiological deafness.

2 The New Zealand Sign Language (NZSL) interpreter had translated the sign as 'diagnosed' but Sally corrected it for us when she reviewed her transcript to the English word she had intended by her sign; a significant shift from medical diagnosis to cultural identity. Note that there are many different Sign Languages so that moving countries may entail learning a new Sign language.

3 Extracts condensed from fieldnotes and transcripts.

4 Alana is Deaf and uses NZsL, Julie and Corinna are hearing and did not know NZSL although Corinna learned quickly. We worked with NZSL-English interpreters except when doing participant observation.

5 This conversation was part of a summer research project in 2011/12 supported by a Royal Society of New Zealand Marsden grant: 'Troubling Choice: exploring and explaining moral reasoning at the intersection of genetic disability and reproductive technology'. In the broader project we are working with a range of organisations and individuals exploring moral reasoning, or 'everyday ethics'.

6 Pseudonyms are used at participants' requests.

7 We had asked Sabine Muller, our liaison person with Deaf communities, to invite a cross-section of people with inherited deafness. Our participants were varied in terms of place of birth. We had hoped that Māori or Pacific people might be involved but this did not eventuate. For an account of Māori Deaf see Smiler (2006).

8 Prenatal and newborn screening can have contradictory effects: creating expectations of a 'perfect newborn' on the one hand, and concerns about imperfections with unknown outcomes on the other (Buchbinder Timmermans, 2011)

9 Barth (1969), and many others subsequently, have discussed the intensely social, international and symbolic nature of ethnic/national/cultural boundaries and theorised that it is the boundary that defines the group. Culturally Deaf people treasure Sign language as the 'overt sign' of their identity and their normalisation of deafness as part of their 'basic value orientation' (Barth, 1969:14); see also Laing (2006). 
10 The contact nature of rugby and possible blows to the head may damage the implant. The pressure changes that accompany diving can also cause damage, although Neil's device is rated by the company to 40 meters. The possibility of damaging it is not worth the risk to Neil.

11 See Savulescu (2002) for further discussion of just such a situation.

\section{REFERENCES}

Barth, F. 1969 Ethnic Groups and Boundaries: The Social Organization of Culture Difference. Bergen: Universitetsforlaget, London: Allen Unwin.

Best, A., Howland, C. and Park, J. 2012 Auckland Deaf Families Study: 'Troubling Choice' Summer Student Research Report. Auckland: University of Otago and University of Auckland Marsden Project UoO1017 Community Report.

Biesold, H. 2002 [1999] Crying Hands: Eugenics and Deaf People in Nazi Germany. Trans. W. Sayers. Washington: Gallaudet University Press.

Brodwin, P. 2000 'Introduction', in P. Brodwin (ed) Biotechnology and Culture: Bodies, Anxieties, Ethics. Bloomington: Indiana University Press:1-26.

Buchbinder, M. and Timmermans, S. 2011 'Medical technologies and the dream of the perfect newborn', Medical Anthropology, 30(1):56-80.

Buzzard, A. and Nicholson, S. 2006 'Deaf parents of Deaf children', SITES N.S., 3(1):126-42.

Crapanzano, V. 2010 [2004] Imaginative Horizons: An Essay in Literary/Philosophical Anthropology. Palo Alto, CA, ebrary [Chicago: University of Chicago Press)].

DPA - Disabled Persons Assembly. 2000 DPA Submission on 'Whakanui Oranga, the NZ Disability Strategy, Question - Barriers'. Retrieved from http://www. dpa.org.nz/what-we-do/projects-and-policy/submissions/184-20oo-dpasubmission-on-whakanui-oranga-the-nz-disability-strategy

Goffman, E. 1963 Stigma: Notes on the Management of Spoiled Identities. Englewood Cliffs, NJ: Prentice Hall.

Groce, N.E. 1985 Everyone Here Spoke Sign Language: Hereditary Deafness on 
Martha's Vineyard. Cambridge MA: Harvard University Press.

Hacking, I. 1996 'Normal people', in D.R Olson and N. Torrence (eds) Modes of Thought: Explorations in Culture and Cognition, Cambridge, Cambridge University Press: 59-71.

Laing, P. 2006 'Migrating to a Deaf world: a model for understanding the experiences of hearing parents of deaf children', SITES N.S., 3(1):75-99.

Latour, B. 1987 Science in Action. Milton Keynes: Open University Press.

Levitas, R. 2003 The Idea of Social Inclusion. Social Inclusion Research Conference. http://www.ccsd.ca/events/inclusion/papers/rlevitas.htm.

Lindgren, K.A., DeLuca, D. and Napoli, D.J. 2008 Signs and Voice: Deaf Culture, Identity, Language, and Arts. Washington, DC: Gallaudet University Press.

McDermott, R. and Varenne, H. 1995 'Culture "as" Disability', Anthropology and Education Quarterly, 26 (3):324-48.

McKee, R.L. 2001 People of the Eye: Stories of the Deaf World. Photographer, Bruce Connew. Wellington: Bridget Williams Books.

McKee, R.L. 2006 'Connecting hearing parents with the Deaf world', SITES N.S., 3(1):143-67.

Mehl, A.L. and Thomson,V. 2002 'The Colorado newborn hearing screening project, 1992-1999: on the threshold of effective population-based universal newborn hearing screening', Pediatrics, 109(1):134.

Ministry of Social Development, Office for Disability Issues, 2001 The New Zealand Disability Strategy: Making a World of Difference - Whakanui Oranga. www.odi.govt.nz/resources/publications/nzds/index.html

Morton, M. 2012 Using DSE to 'Notice, Recognize and Respond' to tools of exclusion and opportunities for inclusion in New Zealand. Review of Disability Studies: An International Journal, 8(3):25-34.

Nance, W.E. 2003 'The genetics of deafness', Mental Retardation and Developmental Disabilities Research Reviews, 9(2):109-19. Retrieved from http://www. ncbi.nlm.nih.gov/pubmed/12784229 
New Zealand Public Health and Disability Act 2000 www.legislation/govt/nz/act/ public/2000/0091/latest/DLM80051.html?src=qs

Sacks, O. 1991 Seeing Voices: A Journey into the World of the Deaf. New rev edn. London: Picador.

Savulescu, J. 2002 'Deaf lesbians, "designer disability," and the future of medicine'. $B M J, 325$ (7367) (October 5):771-73. doi:10.1136/bmj.325.7367.771

Scully, J.L. 2008 Disability Bioethics: Moral Bodies, Moral Difference. Lanham, Rowman Littlefield Publishers, Inc.

Shakespeare, T. 2006 Disability Rights and Wrongs. London: Routledge.

Smiler, K. 2006 'Maori deaf identity', SITES N.S., 3(1):108-25.

Taylor, C. 2002 'Modern social imaginaries', Public Culture, 14(1): 99-124.

Taylor, C. 2007 'Cultures of democracy and citizen efficacy', Public Culture, 19(1): 117-50.

Taylor, T. 2005 'Thomas Hunter and the campaign against eugenics', New Zealand Journal of History, 39(2):195-214.

Walton, W. 2006 'Sign Language as a first language: some experiences of a hearing child of deaf parents', SITES N.S., 3(1):68-82. 